\title{
On the mechanism of the reaction between aryl acetates and hydroxylamine
}

\author{
Deise J. Mazera, José C. Gesser,* and Josefredo R. Pliego \\ Universidade Federal de Santa Catarina, Departamento de Quimica, Campus Universitario, \\ Trindade, Florianopolis, SC 88040-900, Brasil \\ E-mail: gesserjc@yahoo.com.br
}

\begin{abstract}
The reaction of aryl acetates and hydroxylamine produces $O$-acylhydroxylamine and $N$ acylhydroxylamine, the latter being essentially observed for good leaving group esters and the former for poor leaving esters. For both acylation reactions, kinetics studies suggested a tetrahedral intermediate intervention for nucleofuges in a $\mathrm{pKa}$ range of 1 to 9 . Esters having leaving groups with a pKa value less than 7 react by a rate-determining step inferred to be the tetrahedral intermediate formation, while for esters having leaving groups with a $\mathrm{pKa}$ value equal to or higher than 7 , the rate-limiting step has been proposed to be the tetrahedral intermediate decomposition. General bifunctional acid-base catalysis by a second hydroxylamine molecule was identified as one of the components of the reaction for the intermediate collapse to products in the poor leaving group ester
\end{abstract}

Keywords: Aryl acetates, hydroxylaminolysis, hydroxamic acid, hydroxylamine

\section{Introduction}

Its biological importance as well as its synthetic applications have driven numerous mechanistic investigations of the acyl transfer reaction. ${ }^{1-9}$ Besides describing the structural relationships which lead to the reactivity of carboxylic acid derivatives, the search for nucleophiles able to cleave selectively peptide and ester bonds is still a challenge in many areas of chemistry and biochemistry. ${ }^{10-12}$ The development of such stable and highly reactive nucleophiles has a wide range of applications in chemical detoxification, e.g., where quantitative phosphate bond cleavage is the target. ${ }^{13}$ Some researchers in this field have noted that $\alpha$-nucleophiles, such as hydroxylamine, represent a new perspective, but a better understanding of the attacking nucleophilic atom is still to be gained and this has prompted extensive mechanistic studies of the reactions of $\alpha$-nucleophiles with activated acyl derivatives ${ }^{14-20}$, phosphate esters ${ }^{21-29}$ and amides $^{30-33}$. Hydroxylamine is a single $\alpha$-nucleophile, the neutral and anionic forms of which 
ensure high rates of acyl transfer over a wide $\mathrm{pH}$ range and no other known $\alpha$-nucleophile can beat it on its very strong nucleophilicity. ${ }^{34}$

Jencks ${ }^{15,17}$ has described a number of processes whereby acylating agents and ambidentate nucleophiles under controlled conditions can give high yields of the O-acyl derivatives. In the reaction of $p$-nitrophenyl acetate, or $p$-nitrophenyl benzoate, and hydroxylamine, Oacylhydroxylamines are often the initial reaction product, Scheme 1a, but an N-acylated product has also been observed as a minor reaction component of transacylation processes, Scheme $1 \mathrm{~b}$. Under a high concentration of hydroxylamine, additional reaction of product 1a yields the more stable $\mathrm{N}$-acylated product $\mathbf{1} \mathbf{b}^{15}$.

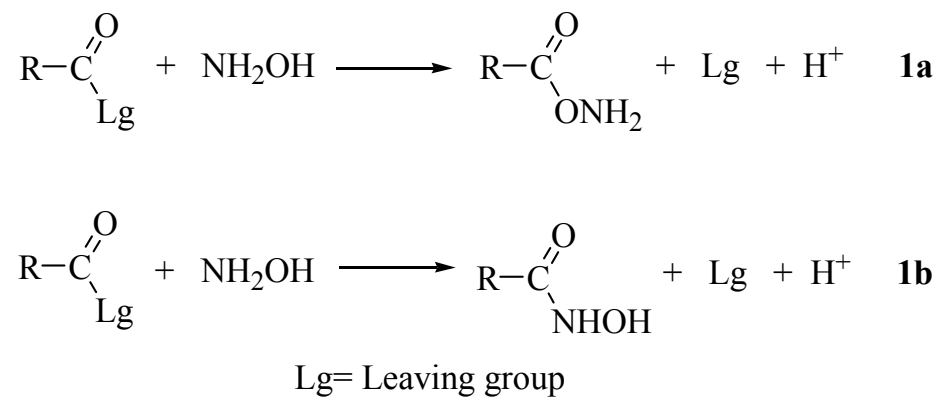

\section{Scheme 1}

For these reactions a multi-step mechanism ${ }^{17}$ has been proposed for O-acylhydroxylamine formation but no suggestions regarding the rate-limiting step have been made. In the late 1990s Hengge $^{19}$, studying kinetic isotope effects in the acyl transfer reaction from $p$-nitrophenyl acetate to hydroxylamine, proposed a rate-limiting step for tetrahedral intermediate decomposition, but no catalytic activity was observed.

Catalytic features of the reaction between phenyl acetate and primary and secondary amines were demonstrated by Jencks and Carriuolo. ${ }^{18}$ Glycine and glycylglycine react through a mechanism requiring general base catalysis by a second molecule of amine. $N, N$-dimethylamine and $N$-butylamine have exhibited specific base catalysis apart from general base catalysis, for methoxyamine only general acid catalysis has been observed and for hydroxylamine the reaction proceeds through simultaneous acid-base general catalysis, but the mechanisms by which the catalytic processes occur have not been discussed.

Whether the mechanism of the reaction between esters and other oxygen and nitrogen nucleophiles is concerted or stepwise is found to be under dispute in the literature. Investigating the reaction of $p$-nitrophenylacetate and phenolate ions, Buncel ${ }^{35}$ described the process as a multi-step reaction and proposed the rate-limiting step to be the intermediate formation, regardless of whether the leaving group departure is synchronized with the nucleophilic attack or not. On the other hand, Williams ${ }^{6 a}$ and Jencks ${ }^{7}$, studying the same reaction have proposed a concerted mechanism based on a constant $\beta_{\mathrm{NU}}$ value even for $\Delta \mathrm{pKa}=0$ when phenolate acts as both the nucleophile and the leaving group. This suggestion is supported by Hengge following 
his kinetic isotope effect studies of reactions between $p$-nitrophenylacetate and several oxyanions, such as, the hydroxyl anion, phenolates, hexafluormethylisopropoxide and aliphatic oxyanions. $^{36}$

Prompted by the controversy regarding the description of the mechanism involved in the reactions of substituted phenyl acetates and hydroxylamine, we report here our kinetics and $a b$ initio studies of reactions between a series of aryl acetates and hydroxylamine. This investigation was directed towards an understanding of $\alpha$-nucleophile reactivity and selectivity in the $\mathrm{N}$ - and $\mathrm{O}$-acylation reactions and its correlation with aryl acetate structures.

\section{Results and Discussion}

\section{Distribution of products}

In our studies, the reaction of aryl acetates 1-5 and hydroxylamine may be described by two distinct processes: (i) an initial fast reaction of aryl ester and hydroxylamine to produce a mixture of $\mathrm{N}$ - and O-acylated compounds, the composition of which is dependent on the substrate structure, Scheme 1. This process was followed spectrophotometrically by measuring the phenolate ion release at hydroxylamine concentrations from $10^{-4}$ to $10^{-1} \mathrm{M}$, under pseudo first-order kinetics conditions, and (ii) the reaction of conversion of the O-acylated compound to the hydroxamic acid at high concentrations of hydroxylamine, Scheme $1 \mathrm{~b}$.

At a hydroxylamine concentration range of 0.05 to $0.2 \mathrm{M}$ the formation of hydroxamic acid from $\mathrm{O}$-acetylhydroxylamine proceeds at a measurable rate and follows pseudo first-order kinetics after an initial fast reaction attributed to the yielding of some hydroxamic acid as described by Equation 1b. No unusual change for each rate constant, associated with the structural features of the substrate, was observed over the whole range of hydroxylamine concentration analyzed, indicating that the transformation monitored was the conversion of $O$ acylhydroxylamine to $N$-acylhydroxylamine. This reaction, described in assay 2 , was not completely studied since the current authors consider it unlikely that this process will contribute directly to elucidating the ambiguity regarding the hydroxylamine atom which carries out the nucleophilic attack, but an elegant analysis of such a process for n-butylthiolacetate has been presented by Bruice and Fedor. ${ }^{37}$

The relative extent of $\mathrm{N}$-acylation observed from an analysis of the data in Table 1 was found to change widely with the nature of the acylating agent, ranging from 53\% for 2,4-dinitrophenyl acetate (DNPA) to a only small amount (1.5\%) for $p$ - chlorophenyl acetate (PCPA). 
Table 1. Second-order rate constants, $\mathrm{k}_{2}\left(\mathrm{M}^{-1} \cdot \mathrm{s}^{-1}\right)$, and third-order rate constants, $\mathrm{k}_{3}\left(\mathrm{M}^{-2} \cdot \mathrm{s}^{-1}\right)$, for substituted phenylester cleavage by $\mathrm{NH}_{2} \mathrm{OH}$ and initial yield of hydroxamic acid produced at 25 ${ }^{\circ} \mathrm{C}, \mathrm{pH} 7.00$ and $\mu=0.50 \mathrm{M}(\mathrm{KCl})$

\begin{tabular}{ccccc}
\hline Ester & $\mathrm{pKa}^{\mathrm{a}}$ & $\begin{array}{c}\mathrm{k}_{2} \times 10^{3} \\
\left(\mathrm{M}^{-1} \cdot \mathrm{sec}^{-1}\right)^{\mathrm{b}}\end{array}$ & $\begin{array}{c}\mathrm{k}_{3} \times 10^{3} \\
\left(\mathrm{M}^{-2} \cdot \mathrm{sec}^{-1}\right)^{\mathrm{b}}\end{array}$ & $\begin{array}{c}\text { Hydroxamic acid formed } \\
\text { in assay 1 } \\
(\% \text { of final value })\end{array}$ \\
\hline $\mathbf{( 1 )}$ & 9.64 & $7.52 \pm 0.02$ & $81.4 \pm 0.2$ & $3.70 \pm 0.03$ \\
$\mathbf{( 2 )}$ & 9.2 & $29.3 \pm 0.2$ & $90.2 \pm 0.2$ & $1.50 \pm 0.27$ \\
$\mathbf{( 3 )}$ & 7.16 & $151.3 \pm 0.1$ & $6,165 \pm 2$ & $16.00 \pm 0.27$ \\
$\mathbf{( 4 )}$ & 4.0 & $32,700 \pm 20$ & --- & $53.00 \pm 3.30$ \\
$\mathbf{( 5 )}$ & 0.38 & $62,200 \pm 300$ & --- & $47.00 \pm 2.34$ \\
\hline
\end{tabular}

a(1) phenyl acetate, (2) $p$-chlorophenyl acetate, (3) $p$-nitrophenyl acetate, (4) 2,4-dinitrophenyl acetate, (5) 2,4,6-trinitrophenyl acetate. ${ }^{\mathrm{b}}$ corrected for free hydroxylamine concentration at $\mathrm{pH}$ 7.00 .

This structural dependence upon product distribution may be attributed to the increased electron withdrawing character of the leaving group throughout the 1-5 ester series, but it should be mentioned that 2,4,6-trinitrophenyl acetate is an exception to this trend of $\mathrm{N}$-acylation extent. The results presented in Table 1 are an average of three experiments and since no nucleophilic aromatic substitution was detected for ester $\mathbf{5}$ the product distribution in this case may reflect the steric hindrance of the 2,4,6-trinitrophenyl group toward the nucleophilic attack of hydroxylamine on the carbonyl carbon, overwhelming the carbonyl group electrophilicity and its selectivity towards the attacking nucleophilic atom of hydroxylamine. In fact, an interpretation of molecular models of 2,4,6-trinitrophenylacetate reveals that the carbonyl group is perpendicular to the aromatic ring. This lack of planarity should decrease the electron withdrawing power of the trinitrophenyl group and promote a decrease in the carbonyl group electrophilicity when compared with other esters in the studied series. The reaction of benzoylchloride and hydroxylamine has been reported to yield $96 \%$ of $\mathrm{N}$-acylated product ${ }^{15}$ which corroborates our interpretation since the high reactivity of this carboxylic acid derivative is frequently attributed to the electron withdrawing power of the chlorine atom and its excellent nucleofugicity, a common explanation given for the reactivity of carboxylic acid derivatives, associating it with the electron withdrawing power and nucleofuge ability of the leaving group.

\section{Kinetics analysis}

As Figure 1A illustrates for $p$-nitrophenyl acetate (PNPA), the observed first-order rate constants for phenyl acetate (PA) and $p$-chlorophenyl acetate (PCPA) also were a quadratic function of total hydroxylamine concentration and a second-order polynomial equation fitting of the curve yielded the $\mathrm{k}_{2}$ and $\mathrm{k}_{3}$ rate constants in Table 1. For dinitrophenyl acetate (DNPA), Figure 1B insert in Figure 1, and trinitrophenyl acetate (TNPA) first-order rate constants were a linear 
function of the total hydroxylamine concentration and the second-order rate constants, $\mathrm{k}_{2}$ in Table 1, were obtained from slopes of plots of the observed first-order rate constants against the nucleophile concentrations.

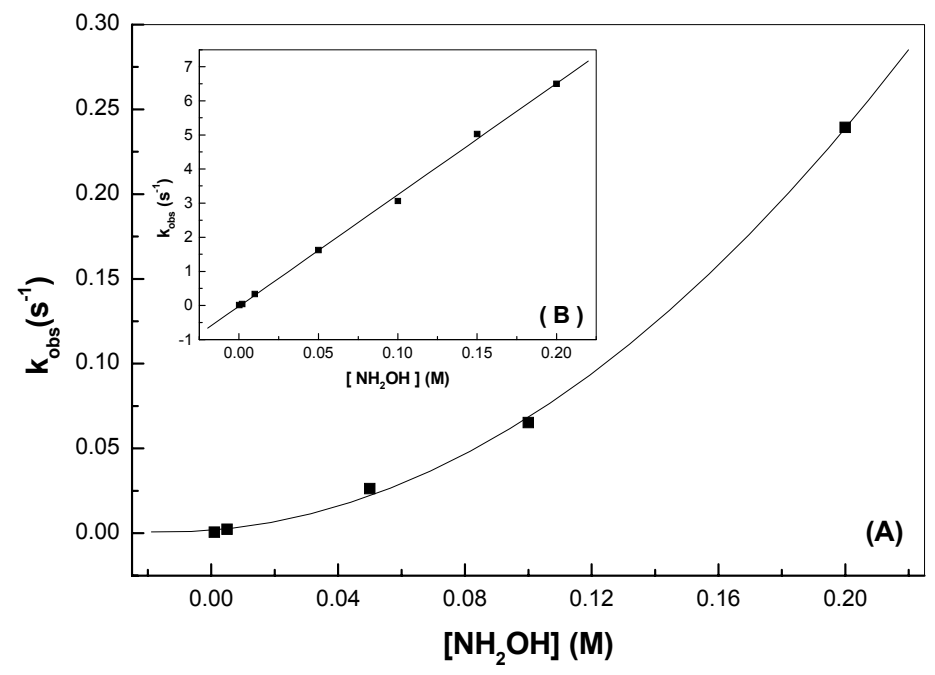

Figure 1. Dependence of pseudo first-order rate constants and total hydroxylamine concentration on $p$-nitrophenyl acetate, (A) and 2,4-dinitrophenyl acetate, (B) at $25^{\circ} \mathrm{C}, \mathrm{pH} 7.00$ and $\mu=0.50$ $\mathrm{M}(\mathrm{KCl})$.

The kinetics data clearly separate the 1-5 aryl ester series into two groups: one reacting through nucleophilic attack by just one hydroxylamine molecule, $\mathrm{k}_{2}$, and the other requiring a second molecule of hydroxylamine, $\mathrm{k}_{3}$. The importance of this second hydroxylamine molecule to the global reaction can also be observed. The PA, PCPA and PNPA (esters 1-3), hereafter referred to as poor leaving group esters, require the aid of a second nucleophile molecule to carry out the reaction whereas DNPA and TNPA (ester 4 and 5), hereafter referred to as good leaving group esters, react directly with a single molecule of hydroxylamine and the reaction goes to completion.

In Table 2, the rate constants accounting for the relative importance of the $\mathrm{N}$ - and O-attack on substituted phenyl acetates as well the magnitude of catalytic effect promoted by the second hydroxylamine molecule in the acyl transfer process are shown. For 1-3 esters the catalyzed reaction corresponds to a minimum of $75 \%$ (entry 2) and to a maximum of $97 \%$ (entry 3 ) of the global reaction and leads to the preferred reaction pathway for poor leaving group esters. It should also be mentioned that for all reactions, unanalyzed and catalyzed by the second hydroxylamine molecule, the rate constants were higher for the O-acylation process indicating that it is the kinetically controlled reaction pathway. 
Table 2. Second-order rate constants, $\mathrm{k}_{2 \mathrm{~N}}\left(\mathrm{M}^{-1} \cdot \mathrm{sec}^{-1}\right)$ and $\mathrm{k}_{2 \mathrm{O}}\left(\mathrm{M}^{-1} \cdot \mathrm{sec}^{-1}\right)$, and third-order rate constants, $\mathrm{k}_{3 \mathrm{~N}}\left(\mathrm{M}^{-2} \cdot \mathrm{sec}^{-1}\right)$ and $\mathrm{k}_{3 \mathrm{O}}\left(\mathrm{M}^{-2} \cdot \mathrm{sec}^{-1}\right)$, for the cleavage of aryl acetates by $\mathrm{NH}_{2} \mathrm{OH}$ at $25^{\circ} \mathrm{C}, \mathrm{pH} 7.00$ and $\mu=0.50 \mathrm{M}(\mathrm{KCl})$

\begin{tabular}{ccccc}
\hline Ester $^{\mathrm{a}}$ & $\begin{array}{c}\mathrm{k}_{2 \mathrm{~N}} \times 10^{3} \\
\left(\mathrm{M}^{-1} \cdot \mathrm{sec}^{-1}\right)^{\mathrm{b}}\end{array}$ & $\begin{array}{c}\mathrm{k}_{2 \mathrm{O}} \times 10^{3} \\
\left(\mathrm{M}^{-1} \cdot \mathrm{sec}^{-1}\right)^{\mathrm{b}}\end{array}$ & $\begin{array}{c}\mathrm{k}_{3 \mathrm{~N}} \times 10^{3} \\
\left(\mathrm{M}^{-2} \cdot \mathrm{sec}^{-1}\right)^{\mathrm{b}}\end{array}$ & $\begin{array}{c}\mathrm{k}_{3 \mathrm{O}} \times 10^{3} \\
\left(\mathrm{M}^{-2} \cdot \mathrm{sec}^{-1}\right)^{\mathrm{b}}\end{array}$ \\
\hline $\mathbf{( 1 )}$ & $0.280 \pm 0.006$ & $7.24 \pm 0.02$ & $3.01 \pm 0.6$ & $78.40 \pm 0.02$ \\
$\mathbf{( 2 )}$ & $0.440 \pm 0.006$ & $28.9 \pm 0.4$ & $1.35 \pm 0.02$ & $88.80 \pm 0.04$ \\
$\mathbf{( 3 )}$ & $24.2 \pm 0.5$ & $127.1 \pm 0.3$ & $986.4 \pm 0.2$ & $5,178 \pm 3$ \\
$\mathbf{( 4 )}$ & $17,330 \pm 40$ & $15,370 \pm 20$ & --- & --- \\
$\mathbf{( 5 )}$ & $29,230 \pm 60$ & $32,960 \pm 30$ & --- & --- \\
\hline
\end{tabular}

a(1): phenyl acetate, (2): p-chlorophenyl acetate, (3): p-nitrophenyl acetate, (4): 2,4-dinitrophenyl acetate, (5): 2,4,6-trinitrophenyl acetate. ${ }^{\mathrm{b}}$ corrected for free hydroxylamine concentration at $\mathrm{pH}$ 7.00 .

\section{Bronsted-type dependence for the transacylation reaction}

Figure 2 shows a Bronsted-type plot for the pKa of the leaving group. The convex curvature observed, the dashed line simply representing the trend of the points, is generally attributed to the formation of an intermediate in the reaction pathway and a change in the rate-limiting step. Hengge has proposed the existence of such an intermediate for the reaction of hydroxylamine and $p$-nitrophenylacetate at low $\mathrm{pH} .{ }^{19}$

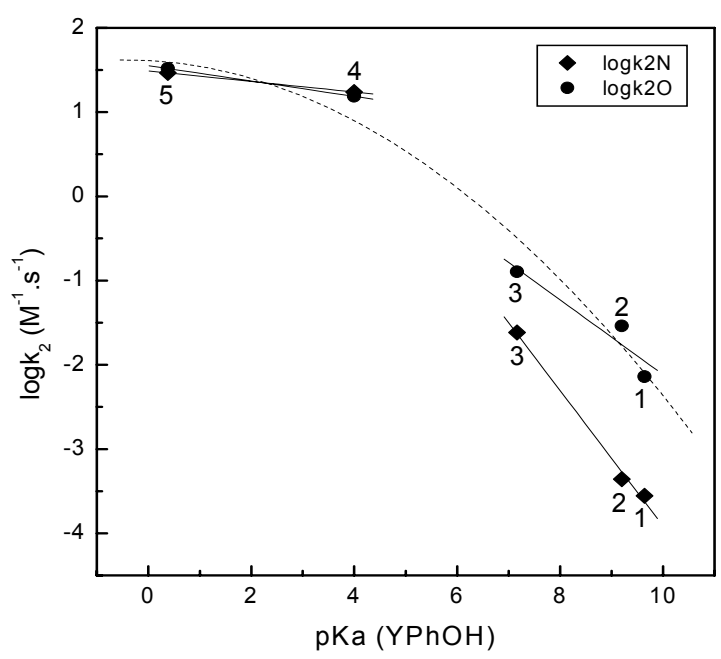

Figure 2. Bronsted-type plot for neutral hydrolysis of aryl acetates by $\mathrm{NH}_{2} \mathrm{OH}$ at $25.0^{\circ} \mathrm{C}$, ionic strength $0.50 \mathrm{M}(\mathrm{KCl})$ and $\mathrm{pH} 7.00(0.01 \mathrm{M}$ phosphate buffer $)$. ( 1 = phenyl acetate, $2=p$ chlorophenyl acetate, $3=p$-nitrophenyl acetate, $4=2$,4-dinitrophenyl acetate and $5=2,4,6$ trinitrophenyl acetate). 
Considering the esters with good leaving groups, with a $\mathrm{pKa}$ lower than 7.0, the bondbreaking process for the leaving group expulsion is incipient, $\beta_{\mathrm{LG}}=0.0627$ and 0.0915 for $\mathrm{k}_{2 \mathrm{~N}}$ and $\mathrm{k}_{2} \mathrm{O}$, respectively, and the bond-making process for the nucleophile probably accounts for the energy barrier necessary to reach the transition state during tetrahedral intermediate formation. However, for those esters with poor leaving groups, with a pKa greater than 7.0, the bondbreaking for the leaving group is advanced, $\beta_{\mathrm{LG}}=0.804$ and 0.444 for $\mathrm{k}_{2 \mathrm{~N}}$ and $\mathrm{k}_{2 \mathrm{O}}$, respectively, indicating a late transition state in the reaction coordinate for which almost all the energy necessary for the leaving group expulsion has already been supplied during the tetrahedral intermediate decomposition. Although it could be considered that the DNPA rate constant values do not deviate significantly from a straight line that could be drawn for all poor leaving group esters, the magnitude of the solvent kinetic isotopic effect (SKIE) that was found for the DNPA reaction was in the same range as that found for TNPA reaction, placing both in the same reaction group, (see next section). Therefore, the data shown in Figure 2 will be taken at this point to imply the presence of a tetrahedral intermediate in the reaction coordinate, leading us to postulate a rate-limiting step for the intermediate formation during the nucleophilic attack by hydroxylamine in the DNPA and TNPA reactions and a change to a rate-limiting step for the intermediate decomposition in the PA, PCPA and PNPA reactions.

A comparison between the second-order rate constant for the cleavage of 1-5 aryl acetates by hydroxylamine yielding both $\mathrm{N}$ - and $\mathrm{O}$-acylated products and that for the hydroxide ion ${ }^{20}$, Figure 3 , gives support to our analysis.

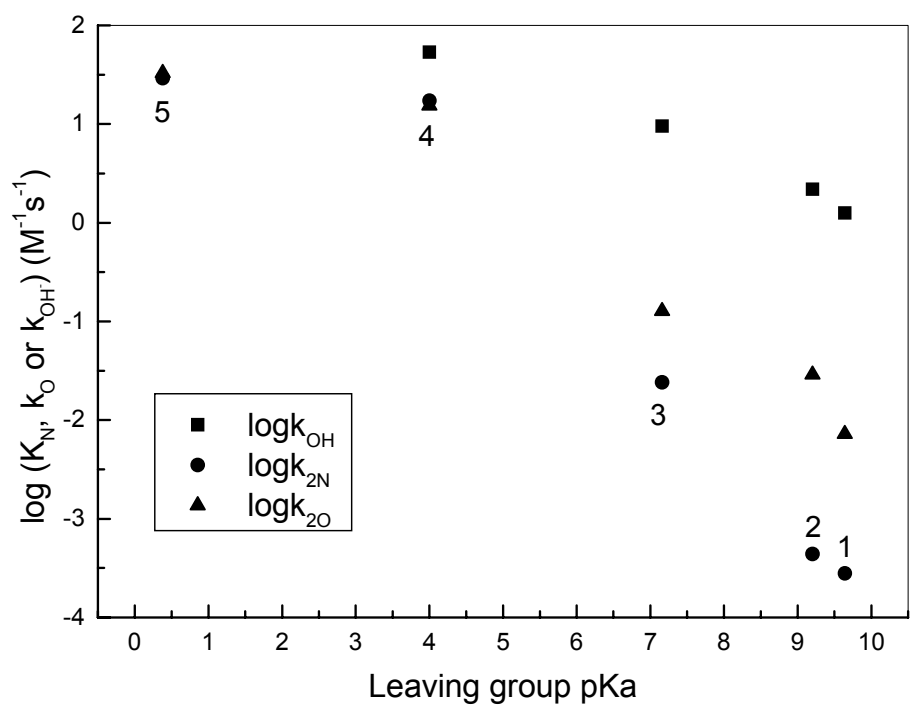

Figure 3. Bronsted plot for the reaction between aryl acetates and hydroxylamine $\left(\bullet=\mathrm{k}_{2 \mathrm{~N}}\right.$ and $\boldsymbol{\Delta}=\mathrm{k}_{2 \mathrm{O}}$ ); hydroxide $\operatorname{ion}^{20}(\boldsymbol{\square})$ at $25^{\circ} \mathrm{C}$ for 1 : phenyl acetate, $2: p$-chlorophenyl acetate, $3: p$ nitrophenyl acetate, 4: 2,4-dinitrophenyl acetate and 5: 2,4,6-trinitrophenyl acetate.

It is expected that the hydroxide ion ( $\mathrm{pKa}$ 15.7) would be much more reactive than hydroxylamine (pKa 6.0) but, as shown in Figure 3, the difference in reactivity between the two 
nucleophiles has a small increase when the nucleofuge ability is gradually reduced. The same conclusion was drawn by Nomura and coworkers. ${ }^{20}$

These results, along with those in Figure 2, allow us to speculate regarding the mechanism for the competition between the $\mathrm{N}$ - and $\mathrm{O}$-acylation reactions of hydroxylamine: for the esters 4 and 5 the $\alpha$ effect is much more relevant since in their case hydroxylamine $(\mathrm{pKa}=5.94)$ is as reactive as the hydroxide ion $(\mathrm{pKa}=15.7)$. This sensitivity to the power of the nucleophile is to be expected only if the rate-limiting step is the tetrahedral intermediate formation. However, the $\alpha$ effect of hydroxylamine is underestimated for esters 1 to 3 as is apparent from the higher reactivity of the hydroxide anion and the sensitivity to the power of the nucleophile indicates the expected generalization: the higher the $\mathrm{pKa}$ of the nucleophile the higher its nucleophilicity and reactivity. Thus, the data in Figure 3 provide further evidence for a tetrahedral intermediate formation in a rate-limiting step when good leaving groups are a structural feature of the ester (4 and 5) and a change of the rate-limiting step to the tetrahedral intermediate decomposition for esters with poor leaving groups ( 1 to 3 ).

The $\log \mathrm{k}_{\mathrm{N}}$ values for the cleavage of 2,4-dinitrophenylacetate by $\alpha$-nucleophiles (rate constants for hydroxylamine, $N$-methyl, $N, N$-dimethyl and $O$-methylhydroxylamine are in Table 3) show a linear relationship with the pKa of the nucleophile, Figure 4.

Table 3. Reaction rates of hydroxylamine derivatives and 2,4-dinitrophenyl acetate at $25.0^{\circ} \mathrm{C}$, ionic strength $0.50 \mathrm{M}(\mathrm{KCl})$ and $\mathrm{pH} 7.00$ ( $0.01 \mathrm{M}$ phosphate buffer)

\begin{tabular}{|c|c|c|c|c|c|}
\hline Nucleophile & $\mathrm{pKa}^{\mathrm{a}}$ & $\begin{array}{c}\mathrm{k}_{2}^{a p p} \\
\left(\mathrm{M}^{-1} \cdot \sec ^{-1}\right)\end{array}$ & $\begin{array}{c}\mathrm{k}_{2}^{\text {corr b,c }} \\
\left(\mathrm{M}^{-1} \cdot \mathrm{sec}^{-1}\right)\end{array}$ & $\begin{array}{c}\mathrm{k}_{\mathrm{N}}^{\mathrm{b}} \\
\left(\mathrm{M}^{-1} \cdot \mathrm{sec}^{-1}\right)\end{array}$ & $\begin{array}{c}\mathrm{k}_{\mathrm{O}}^{\mathrm{b}} \\
\left(\mathrm{M}^{-1} \cdot \mathrm{sec}^{-1}\right)\end{array}$ \\
\hline Hydroxylamine & 5.94 & $30.08 \pm 0.01$ & 32.70 & 17.33 & 15.37 \\
\hline $\begin{array}{l}N \text {-methyl } \\
\text { hydroxylamine }\end{array}$ & 6.18 & $36.64 \pm 0.02$ & 42.13 & 25.28 & 16.85 \\
\hline $\begin{array}{l}N, N \text {-dimethyl } \\
\text { hydroxylamine }\end{array}$ & 5.20 & $5.14 \pm 0.01$ & 5.23 & 0 & 5.23 \\
\hline $\begin{array}{l}\text { O-methyl } \\
\text { hydroxylamine }\end{array}$ & 4.62 & $1.19 \pm 0.03$ & 1.19 & 1.19 & 0 \\
\hline
\end{tabular}

${ }^{\mathrm{a}}$ Dissociation constants are from the NIST Standard Database Reference 46, Version 6.0, NIST, Standard Reference Data, Gaithersburg. ${ }^{b}$ the rate constants are derived from $\mathrm{k}_{2}{ }^{\text {app }}$ and have the same error. ${ }^{\mathrm{c}}$ corrected for free nucleophile concentration at $\mathrm{pH}$ 7.00.

The slope of the straight line for the Bronsted-type plot is 0.86 . Comparing this value with a $\beta_{\mathrm{NU}}$ of 0.51 for the reaction of secondary aliphatic amines and the same substrate ${ }^{39}$, we may conclude that the bond between hydroxylamine and the electrophilic centre has a higher extent of formation than that of the other nitrogen nucleophiles shown in the Figure 4 . Therefore $\beta_{\mathrm{NU}}$ is a 
parameter indicating a later transition state in the reaction coordinate, which is to be expected considering the high $\alpha$-nucleophile efficiency of hydroxylamine.

On comparing the $\beta_{\mathrm{NU}}$ value of 0.86 and the $\beta_{\mathrm{LG}}$ value of 0.091 (calculated from the experiment in Figure 2), for $\mathrm{N}$-acylation reaction, we may identify again a rate-limiting transition state with a high degree of bond-formation for the nucleophile and a low degree of bondbreaking for the leaving group in the DNPA reaction, both corresponding to the higher energy step of the possible stepwise mechanism. Therefore, the highest energetic demand for the reaction pathway may be associated with the reaching of the transition state for the tetrahedral intermediate formation. The results made clear that the leaving group expulsion is an event in the reaction coordinate, so the $\beta_{\mathrm{LG}}$ value may also be used to exclude the formation of an acylium ion as a possible pathway for the reaction since the leaving group is still bound in the proposed intermediate structure.

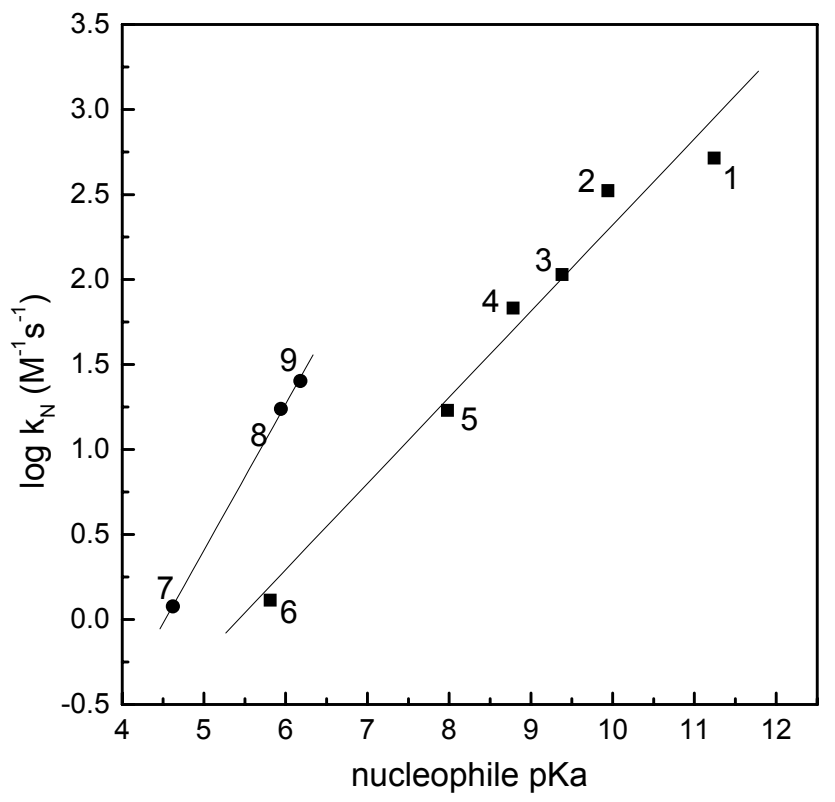

Figure 4. Bronsted-type plot for hydrolysis of 2,4-dinitrophenyl acetate at $\mathrm{pH} 7.00$ with $\alpha$ nucleophiles at $25.0^{\circ} \mathrm{C}$, ionic strength $0.50 \mathrm{M}(\mathrm{KCl})$ and $0.01 \mathrm{M}$ phosphate buffer $(9=\mathrm{N}-$ methylhydroxylamine, $8=$ Hydroxylamine, $7=O$-methylhydroxylamine) and secondary aliphatic amines at ionic strength $0.20 \mathrm{M}, 0.01 \mathrm{M}$ borate or phosphate buffer ${ }^{39},(6=$ piperazinium ion, 5 = 1-formylpiperazine, $4=$ morpholine, $3=1-(\beta$-hydroxymethyl $)$ piperazine, $2=$ piperazine, $1=$ piperidine $)$.

\section{Solvent kinetics isotope effect analysis}

The acylation reaction showed an inverse solvent kinetics isotope effect in the range of 0.70 $0.80 \pm 0.01$ for good leaving group esters, which excludes general bifunctional acid-base catalysis since a linear correlation between the observed rate constant and hydroxylamine 
concentration was detected in the experiments. As discussed in the previous section, DNPA was grouped with TNPA in the Bronsted-type correlation diagram analysis considering the magnitude of SKIE observed for both. The inverse SKIE may be correlated in this case to the better nucleophilicity of deuterated hydroxylamine most likely occurring during its direct attack on esters 4 and 5 in a rate-limiting step corresponding to the tetrahedral intermediate formation. The normal SKIE in the range 1.4-1.5 \pm 0.1 was observed for poor leaving group esters and has also been observed by Jencks and Carriuolo. ${ }^{14}$ Although a higher SKIE would be expected for a proton transfer in the rate-limiting step we should consider that, as will be shown later in the molecular modeling analysis, if the hydrogen bond-making or hydrogen bond-breaking processes for the rate-determining step transition state are still taking place, but the extent of proton transfer is small for both directions in the global reaction, the observed magnitude of SKIE may be attributed to the intervention of bifunctional general bifunctional acid-base catalysis by a second hydroxylamine molecule mediating the proton transfer to the leaving group, a conclusion also substantiated by a reaction order of more than one for hydroxylamine.

\section{Molecular modeling analysis}

To verify the importance of the hydroxylamine catalyst on the rate-limiting step, the reaction coordinates were mapped by ab-initio molecular modeling using the HF/6-31G(d) base set and electronic energies determined at the B3LYP/6-311+G(2df,2p) level of theory. Computation of solvation effects was considered at Polarized Continuum Model (PCM) accuracy. The results discussed hereafter are those for phenyl acetate, thought to represent poor leaving group esters in the 1-5 series studied. Figure 5 can be taken as a representation of the rate-limiting step transition state for $O$-acylhydroxylamine (TS2O) and $N$-acylhydroxylamine (TS2N) decomposition from aryl acetates (1-3) which have a calculated activation free energy barrier of $18.99 \mathrm{Kcal}^{\mathrm{mol}}{ }^{-1}$ and $19.46 \mathrm{Kcal}^{\mathrm{mol}}{ }^{-1}$, respectively.

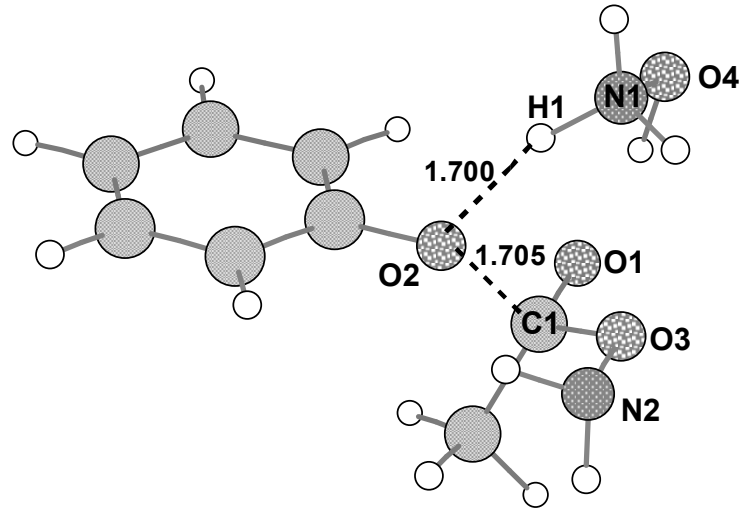

TS2O

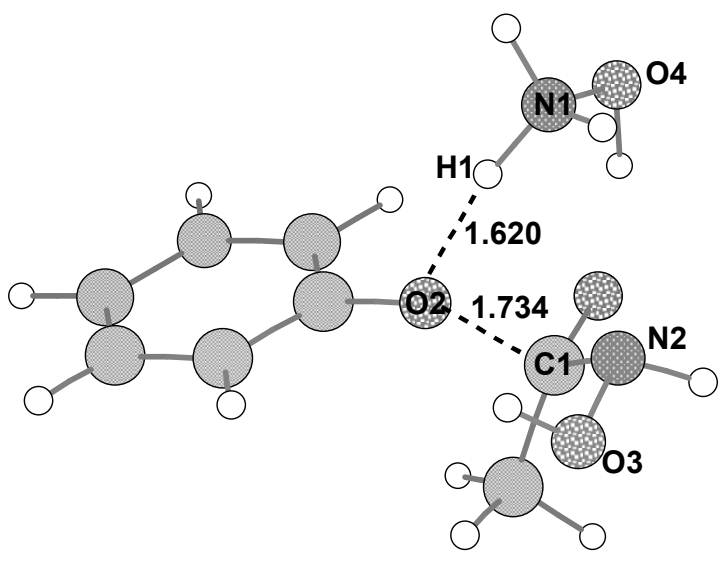

TS2N

Figure 5. Representation of rate-limiting step transition state for the intermediate decomposition of $N$-acylhydroxylamine (TS2N) and $O$-acylhydroxylamine (TS2O). 
Of all other transition state energies determined, these values were the lowest energies values found between the mapped transition states and are the closest to the experimental value of 19.78 $\mathrm{Kcal}_{\mathrm{mol}}{ }^{-1}$. These conjugated factors set the transition state structures to be used in our analysis since the energy barriers for the tetrahedral intermediate formation of $\mathrm{O}$ and $\mathrm{N}$-acylated hydroxylamine were 18.60 and $17.42 \mathrm{Kcal}^{\mathrm{mol}}{ }^{-1}$, respectively.

As can be seen, a second hydroxylamine molecule acts in the global reaction as a bifunctional catalyst promoting an intramolecular proton transfer from the carbinolamine hydroxylic oxygen, $\mathrm{O} 1$, to the $\mathrm{O} 4$ of the zwitterionic form of hydroxylamine and from the ammonium nitrogen atom of hydroxylamine, $\mathrm{N} 1$, to the phenoxide oxygen, $\mathrm{O}_{2}$, in the tetrahedral intermediate decomposition of the $\mathrm{N}$-acylation reaction. In fact, the first proton transfer process described above, from $\mathrm{O} 1$ to $\mathrm{O} 4$, occurred almost completely, $\mathrm{d}_{\mathrm{O} 4-\mathrm{H}}=1.011$. The second proton transfer process, $\mathrm{N} 1-\mathrm{O} 2$, is in its very initial stage, $\mathrm{d}_{\mathrm{N} 1-\mathrm{H} 1}=1.049 \AA$, and is $0.103 \AA$ away from the standard NH bond distance of $0.946 \AA$ found by molecular modeling of the starting material, Figure $5-$ TS2N. These values indicate a low extent of hydrogen transfer for the nucleofuge expulsion in TS2. This low extent of hydrogen transfer may explain the small normal SKIE observed for poor leaving group esters in the previous section. Tetrahedral intermediate decomposition of the O-acylation process occurs via the same prototropism, Figure 5 - TS2O, and in both cases the zwitterionic form of hydroxylamine is stabilized by the hydrogen bond present before the formation of the first transition state.

As discussed in the Bronsted-type analysis section, the transition state occurs quite late, $\mathrm{C} 1$ $\mathrm{O} 2$ bond breaking is advanced in the reaction coordinate $\left(\mathrm{d}_{\mathrm{C} 1-\mathrm{O} 2}=1.705 \AA\right.$ for O-Acylation and $\mathrm{d}_{\mathrm{C} 1-\mathrm{O} 2}=1.734 \AA-\mathrm{N}$-acylation), but the proton transfer to the leaving group expelled in the $\mathrm{N}$ acylation reaction is delayed $\left(\mathrm{d}_{\mathrm{O} 2-\mathrm{H} 1}=1.620 \AA\right)$ when compared with that for O-acylation $\left(\mathrm{d}_{\mathrm{O} 2-\mathrm{H} 1}=\right.$ $1.700 \AA$ ). In both cases, the extent of proton transfer is low justifying the small normal observed SKIE and the $\pi$-carbonyl system restoration pathway for the product formation is, in our view, the driving force for the $\mathrm{C}-\mathrm{O}$ nucleofuge bond-breaking. The results presented here are consistent with the mechanism proposed for poor leaving group esters in Scheme 2 and lead us to conclude that the free activation energy for $\mathrm{N}$-acylated hydroxylamine intermediate decomposition is higher than that for O-acylated hydroxylamine intermediate decomposition, but tetrahedral intermediate formation has a lower energy barrier for the former. 


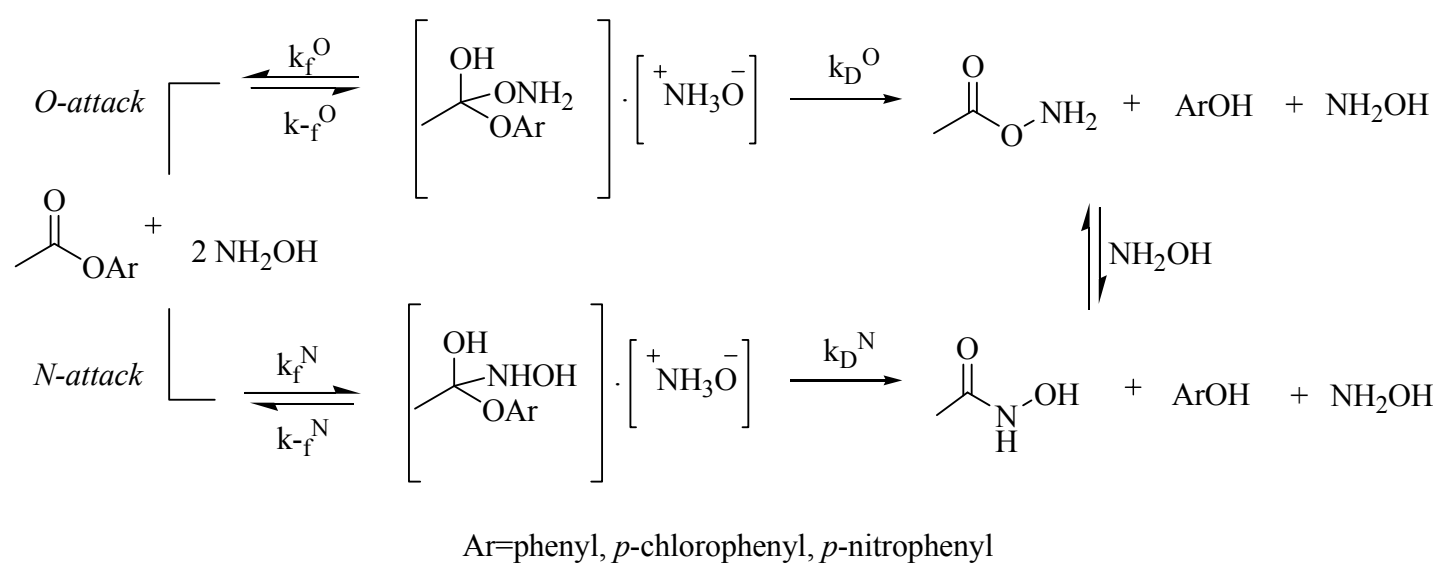

\section{Scheme 2}

Assuming an equilibration processes for the neutral tetrahedral intermediate cleavage, the regeneration of starting materials, in the proposed mechanistic scheme, is more pronounced for formation of the $\mathrm{N}$-acylation reaction product. Consequently, most of the $\mathrm{N}$-acylintermediate should decompose to its starting material faster than to the products. On the other hand, the Oacylintermediate should decompose to products much more easily when formed, which helps to explain the product distribution given in Table 1 .

The computational studies demonstrated that in the neutral tetrahedral intermediate (structure not shown) the $\mathrm{O}-\mathrm{H}$ distance of the neutral protonated carbonyl oxygen is $1.12 \AA$. This calculated distance is $0.17 \AA$ longer than the $0.96 \AA$ for a regular $\mathrm{O}-\mathrm{H}$ hydroxylic bond in an alcohol and the carbonyl oxygen even protonated should have, although we did not calculate the charge distribution in the molecule, a higher charge density than in the neutral hydroxyl group. But the fully anionic character of carbonyl oxygen will be observed only when the rate-determining transition state is reached, for phenyl acetate the $\mathrm{pKa}$ of the transition state calculated by Segreda $^{40}$ is 3.0 .

The reaction coordinate map for good leaving group esters is under investigation but suggests a mechanistic scheme which should follow the same principles described above. Thus, the reaction coordinate map should keep essentially the same shape only with a change in the ratedetermining step. Due to the higher nucleophilicty of the nitrogen atom, the tetrahedral intermediate generated from the $\mathrm{N}$-attack will accumulate faster, but now the tetrahedral intermediate formed will accumulate and decompose easily to the products, explaining the increase in the $\mathrm{N}$-acylated compound distribution.

In the light of this mechanistic scheme, Jenck's ${ }^{17}$ assertion that "the high reactivity of the hydroxylamine oxygen atom in this reaction requires some specific interaction of the hydroxylamine with the carbonyl group and this is not an intrinsic property of the oxygen atom since alkylation of hydroxylamine occurs on the nitrogen atom", later interpreted by Hengge ${ }^{19}$ as a bifurcated three-centre hydrogen bond, may be reconsidered assuming that the initial interaction of the hydroxylamine and carbonyl group should develop a partial positive charge on 
the hydroxylamine nucleophilic attacking atom. This partial charge will be better accepted by the more polarizable nitrogen atom, decreasing the energy barrier to the tetrahedral intermediate formation for $\mathrm{N}$-acylation more than for $\mathrm{O}$-acylation. Once formed, the tetrahedral intermediate decomposition is, besides other factors, aided by the push of the electron of the hydroxylamine nucleophilic attacking atom. This electron release is affected by the electronegativity of the $\alpha$ atom of the hydroxylamine which will decrease the activation energy for decomposition of the tetrahedral intermediate generated from $\mathrm{O}$-acylation more than that generated from the $\mathrm{N}$ acylation reaction.

\section{Conclusions}

Our investigation proposes a stepwise mechanism for the reaction of a series of substituted phenylacetates, PA, PCPA, NPA, DNPA, TNPA and hydroxylamine. Kinetics data separate all the series into distinct classes of esters: (i) those reacting through a direct nucleophilic attack of hydroxylamine and (ii) those requiring a second molecule of the nucleophile to carry out the reaction. Bronsted-type experiments give support to the inference of a tetrahedral intermediate formation in the reaction and a rate-determining step change for the 1-5 ester series. The solvent kinetics isotope effects are added as input data to infer the importance of proton transfer processes and revalidate our proposition of a rate-limiting transition state formation for good leaving group esters and a rate-limiting transition state decomposition for poor leaving group esters. A comparison between the sensitivity of the structure of esters and the nucleophile power of the hydroxide ion and hydroxylamine was also used to identify the rate-limiting step for the studied esters series. The calculated reaction coordinate map identified a rate-limiting step for the decomposition of the tetrahedral intermediate aided by a proton transfer process promoted by a second molecule of hydroxylamine in the reaction of poor leaving group esters, but to a low extent, which aids an interpretation of the small normal solvent isotopic effect observed.

\section{Experimental Section}

General Procedures. The hydroxylamine, $N$-methylhydroxylamine, $N, N$-dimethylhydroxylamine, $O$-methylhydroxylamine, purchased from Aldrich, were neutralized before use in the aqueous stock solution preparation. Phenyl acetate was commercially obtained from Aldrich in the grade appropriate for kinetics assays and was used as purchased. Substituted phenylesters were prepared by reaction of acetic anhydride with the respective phenol as described in the literature, ${ }^{41}$ recrystallized from an ethyl ether-hexane mixture and characterized by their melting points: $p$-nitrophenylacetate m.p. $=80-82 \quad\left(\right.$ lit $\left.^{42}=79-80\right) ; 2,4$-dinitrophenyl acetate m.p. $=73$ $\left(\right.$ lit $\left.^{43}=72-73\right)$ and 2,4,6-trinitrophenyl acetate m.p. $=95\left(\right.$ lit $\left.^{44}=96\right) . p$-chlorophenyl acetate was synthesized as a yellowish oil and characterized by comparing its IR and NMR absorption 
spectra with those described in the literature. ${ }^{45}$ All other reagents $\left(\mathrm{FeCl}_{3} \cdot 6 \mathrm{H}_{2} \mathrm{O}\right.$, chloridic acid and sodium hydroxide, acetonitrile, buffers and deuterated solvents) were commercially obtained and used as purchased.

\section{Kinetics}

Acylation reaction. Assay 1. The kinetics studies of the substituted phenylacetate and hydroxylamine reaction, yielding $\mathrm{O}$-acetylated and $\mathrm{N}$-acetylatedhydroxylamines (hydroxamic acids), Scheme 1a-b, were performed using an HP8452A UV-Vis spectrophotometer for slow reactions $\left(t_{1 / 2} \geq 10 \mathrm{~s}\right)$ and an SX.18MV stopped-flow spectrophotometer for fast reactions $\left(t_{1 / 2}<\right.$ $10 \mathrm{~s}$ ), both coupled to a Microquimica MQBTC 99-20 thermostated bath to keep the reaction mixture temperature at $25.0 \pm 0.1^{\circ} \mathrm{C}$. The reactions were followed by monitoring the leaving group expulsion at the fixed wavelength corresponding to the maximum absorption $\left(\lambda_{\max }\right)$ of the respective phenolate. In a typical transacylation run a sufficient quantity of ester was added to 3 $\mathrm{mL}$ of $\alpha$-nucleophile buffered solution to guarantee $10^{-5} \mathrm{M}$ final ester concentration. The $\alpha$ nucleophile concentration was kept 10 to 100 times higher than the substrate concentration to ensure strictly pseudo first-order kinetics. Ionic strength was set at $0.50 \mathrm{~mol} . \mathrm{dm}^{-3}$ using $\mathrm{KCl}$. Solutions were buffered using $0.01 \mathrm{M}$ phosphate at $\mathrm{pH} 7.00$. The nucleophile stock solution was prepared in a volumetric flask just before use and transferred by Hamilton Gastight syringes. Observed first-order rate constants $\left(k_{\text {obs }}\right)$ were calculated through a nonlinear least-squares fitting of the absorbance versus time, using UV-Vis HP8254A software, by averaging three typical runs. The solvent kinetics isotope effect was analyzed using hydroxylamine solutions prepared in $\mathrm{D}_{2} \mathrm{O}$ with the $\mathrm{pD}$ adjusted to $7.00(\mathrm{pH} 6.60)$ using a $\mathrm{NaOD}$ or $\mathrm{DCl}$ solution as required.

N-Acylation extent detection. Assay 2. $50 \mathrm{~mL}$ of a buffered solution (0.01M phosphate) of 0.05 to $0.20 \mathrm{M}$ hydroxylamine $\left(0.50 \mathrm{M} \mathrm{KCl}\right.$ ionic strength) was thermostated at $25.0 \pm 0.1^{\circ} \mathrm{C}$ and a solution of the respective substrate was added to ensure $7 \times 10^{-4} \mathrm{M}$ acetate concentration. At this high hydroxylamine concentration the first reaction yielding $\mathrm{N}$ - and $\mathrm{O}$-acetylated compounds was very fast as detected by spectrophotometric experiments. After the first reaction was observed to have finished, $\mathrm{N}$-acetylatedhydroxylamine (hydroxamic acids) was quantified as the $\mathrm{FeCl}_{3}$ complex, using a modified procedure of Lipmann and Tuttle ${ }^{46}$ adding $0.50 \mathrm{~mL}$ of $10 \%$ $\mathrm{FeCl}_{3} \cdot 6 \mathrm{H}_{2} \mathrm{O}$ acidic stock solution, prepared to give a $0.20 \mathrm{~N} \mathrm{HCl}$ final concentration, and $0.50 \mathrm{~mL}$ of $\mathrm{HCl} / \mathrm{H}_{2} \mathrm{O} 50 \%(\mathrm{v} / \mathrm{v})$ to $3 \mathrm{~mL}$ of the reaction mixture. Samples were collected at appropriate intervals. The absorbance was measured at $540 \mathrm{~nm}$ and found to increase linearly with hydroxamic acid concentration within the working range of the instrument.

Initial yield of hydroxamic acid. The relative amounts of $\mathrm{O}$ - and $\mathrm{N}$-acylation yielded in the initial fast reaction could therefore be estimated by adding the acylating agent to the moderately concentrated hydroxylamine solutions. Monitoring the formation of hydroxamic acid at different times and extrapolating the first points to zero time gave us, in comparison with the final amount 
of $\mathrm{N}$-acylated product, the relative initial amount of $\mathrm{N}$-acylated compound formed during the first reaction described above.

\section{Acknowledgements}

We thank the Conselho Nacional de Desenvolvimento Científico e Tecnológico, (CNPq) and CAPES for financial support. Thanks also to Professor Faruk Nome for his help in the research development and elucidating support in the mechanistic discussion and to Gizelle Almerindo for her helpful advice on ab-initio molecular modeling.

\section{References and Notes}

1. Andrés, G. O.; Rossi, R. H. Arkivoc 2004, 127.

2. Adalsteinsson, H.; Bruice, T. C. J. Am. Chem. Soc. 1998, 120, 3440. DOI: 10.1021/ ja972162+.

3. Jencks, W. P.; Gilchrist, M. J. Am. Chem. Soc. 1968, 90, 2622.

4. (a) Castro, E. A.; Leandeo, L.; Quesieh, N.; Santos, J. G. J. Org. Chem. 2001, 66, 6130. DOI: 10.1021/jo0157371. (b) Castro, E. A.; Cubillos, M.; Santos, J.G. J. Org. Chem. 2001, 66,: 6000. DOI: $10.1021 /$ jo0100695

5. Um, I. H.; Min, J. S.; Ahan, J. A.; Han, H. J. J. Org. Chem. 2000, 65, 5659. DOI: 10.1021/jo000482x.

6. (a) Ba-Saif, S.; Luthra, A. K.; Williams, A. J. Am. Chem. Soc. 1987, 109, 6362. (b) Bourne, N.; Chrystiuk, E.; Davis, A. M.; Williams, A. J. Am. Chem. Soc. 1988, 110, 1890. (c) Deacon, T.; Farrar, C. R.; Sikkel, B. J.; Williams, A. J. Am. Chem. Soc. 1978, 100, 2625.

7. Stefanidis, D.; Cho, S.; Dhe-Paganon, S.; Jencks, W. P. J. Am. Chem. Soc. 1993, 115, 1650.

8. (a) Andres, G. O.; Granados, A. M.; Rossi, R. H. J. Org. Chem. 2001, 66, 7653. DOI: 10.1021/jo010499v. (b) Fernandez, M. A.; Rossi, R. H. J. Org. Chem. 1999, 64, 6000. DOI: 10.1021/jo990550j.

9. Castro, E. A.; Angel, M.; Arellano, D.; Santos, J. G. J. Org. Chem. 2001, 66, 6571. DOI: 10.1021/jo0101252.

10. Terrier, F.; MacCormack, P.; Kizilian, E.; Halle, C.; Demerseman, P.; Guir, F.; Lion, C. J. Chem. Soc. Perkin Trans. 2. 1991, 153.

11. Terrier, F.; Degorre, F.; Kiffer, D.; Laloi, M. Bull. Soc. Chim. Fr. 1988, 2, 415.

12. Tarkka, R. M.; Buncel, E. J. Am. Chem. Soc. 1995, 117, 1503.

13. Domingos, J. B.; Longhinotti, E.; Machado, V. G.; Nome, F. Quim. Nova 2003, $26,745$.

14. Jencks, W. P.; Carriuolo, J. J. Am. Chem. Soc. 1960, 82, 1778.

15. Jencks, W. P. J. Am. Chem. Soc. 1958, 80, 4581.

16. Gerstein, J.; Jencks, W. P. J. Am. Chem. Soc. 1964, 86, 4655. 
17. Jencks, W. P. J. Am. Chem. Soc. 1958, 80, 4585.

18. Jencks, W. P.; Carriuolo, J. J. Am. Chem. Soc. 1960, 82, 1778.

19. Hess, R. A. Hengge, A. C.; Cleland, W. W. J. Am. Chem. Soc. 1997, 119, 6980. DOI: 10.1021/ja970648k.

20. Nomura, Y.; Kubozono, T.; Hidaka, M.; Horibe, M.; Mizushima, N.; Yamamoto, N.; Takahashi, T.; Komiyama, M.; Bioorg. Chem. 2004, 32, 26.

21. Li, Z. K. et al. Arkivoc 2005, 98.

22. Kirby, A. J.; Dutta-Roy, N.; da Silva, D.; Goodman, J. M.; Lima, M. F.; Roussev, C. D.; Nome, F. J. Am. Chem. Soc. 2005, 127, 7033. DOI: 10.1021/ja0502876

23. Kirby, A. J.; Lima, M. F.; Silva, D.; Nome, F. J. Am. Chem. Soc. 2004, 126, 1350. DOI: 10.1021/ja038428w

24. Asaad, N.; Kirby, A. J. J. Chem. Soc., Perkin Trans. 2. 2002, 1708.

25. Kirby, A. J.; Marriott, R. E. Recl. Trav. Chim. Pays-Bas. 1996, 115, 56.

26. Chandler, A. J.; Kirby, A. J. J. Chem. Soc., Chem. Commun. 1992, 1769.

27. Herschlag, D.; Jencks, W. P. J. Am. Chem. Soc. 1989, 111, 7579.

28. Kirby, A. J.; Jencks, W. P. J. Am. Chem. Soc. 1965, 87, 3209.

29. Kirby, A. J.; Jencks, W. P. J. A;m. Chem. Soc. 1965, 87, 3217.

30. Jencks, W. P.; Gilchrist, M. J. Am. Chem. Soc. 1964, 86, 5616.

31. Buurma, N. J.; Blandamer, M. J.; Engberts, J. B. F. N. J. Phys. Org. Chem. 2003, 16, 438. DOI: $10.1002 /$ poc. 607.

32. Kaplan, O.; Nikolaou, K.; Pisvejcova, A.; Martinkova, L. Enzyme Microb. Technol. 2006, 38, 260.

33. Buckingham, D. A.; Clark, C. R. Met. Ions Biol. Syst. 2001, 38, 43.

34. Simanenko, S.; Popov, A. F.; Prokop'eva, T. M.; Karpichev, E. A.; Savelova, V. A.; Suprun, I. P.; Bunton, C. A. Russ. J. Org. Chem. 2002, 38, 1286.

35. Buncel, E.; Um, I. H.; Hoz, S. J. Am. Chem Soc. 1989, 111, 971.

36. Hess, R. A.; Hengge, A. C. J. Am. Chem. Soc. 1994, 116, 11256.

37. Bruice, T.; Fedor, L. R. J. Am. Chem. Soc. 1964, 86, 739.

38. Weast, R. C. Handbook of Chemistry and Physics, CRC Press.: Florida, 1979.

39. Castro, E. A.; Ureta, C. J. Org. Chem. 1990, 55, 1676.

40. Segreda, J. F. M. Arkivoc 2003, 550.

41. Kirkien-Konasiewicz, A.; Maccoll, A. J. Chem. Soc. 1964, 1267.

42. Ueda, M.; Seki, K.; Imai, Y. Synthesis 1981, 12, 991.

43. Kita, Y.; Akai, S.; Yamamoto, M.; Taniguchi, M.; Tamura, Y. Synthesis 1989, 4, 334.

44. Kurts, A. L.; Davydov, D. V.; Bundel, Y. G. Vestn. Mosk. Univ., Ser. 2: Khim. 1983, $24,73$.

45. Chattaway, F. D. J. Chem. Soc. 1931, 134, 2495.

46. Lipmann, F.; Tuttle, L. C. J. Biol. Chem. 1945, 159, 21. 